\title{
AVALIAÇÃO CRÍTICA DE UMA EXPERIÊNCIA DE ENSINO-APRENDIZAGEM
}

\section{A CRITICAL VIEW OF A LEARNING-AND-TEACHING}

\author{
Roselisa Crespi MARTINS*
}

\begin{abstract}
RESUMO
O presente trabalho, desenvolvido como atividade prática durante a disciplina Ensino da Psicologia Clínica, do curso de Mestrado em Psicologia Clínica da PUC-Campinas, teve por objetivo realizar a análise crítica de uma prática de ensino à escolha do aluno. Tomando-se a atividade de ensino dentro de uma concepção mais ampla, que envolve a reciprocidade entre as pessoas envolvidas no processo, escolheu-se a relação terapêutica como a experiência de ensino-aprendizagem a ser analisada. Utilizou-se a Versão de Sentido (vs) como forma de registro de 9 sessões de um caso, atendido em psicoterapia breve de orientação psicodinâmica. Os relatos (vs) são pensados em termos de sua articulação com as tendências pedagógicas, seguindo-se a análise crítica dessa experiência.
\end{abstract}

Palavras-chave: versão de sentido, tendências pedagógicas, práticas de ensino, avaliação crítica da aprendizagem, psicoterapia breve.

\section{ABSTRACT}

\section{A CRITICAL VIEW OF A TEACHING-AND-LEARNING EXPERIENCE}

This research was conducted as a practical activity while attending classes on the subject ofTeaching Clinical Psychology during the Master formation in Clinical Psychology at PUC-Campinas. The main objective was to exercise a critical analysis of a teaching practice chosen by the student. From a wider view of teaching-and-learning processes and considering the cooperatively interation between the involved parties, the therapeutic relation was selected as an experience of this kind to be analysed. A methodology named Felt Sense Report was employed to register 9 sessions of brief psychodynamical therapy. The data were submitted to a critical analysis based on its articulations with pedagogical tendencies.

Key-words:Felt Sense Report, pedagogical tendencies, teaching-and-learning practices, critical evaluation of learning processes, brief psychotherapy.

*) Doutoranda em Psicologia como Profissão e Ciência pela PUC-Campinas.

Endereço para correspondência: Rua Genebra, no230, apto 102. CEP:01316-010- Bela Vista, São Paulo/SP.

E-mail: roselisa@uol.com.br 


\section{INTRODUÇÃO}

A educação não se processa num vácuo cultural. Ela cumpre finalidades sociais, espelha condicionantes sociopolíticos, pressupondo diferentes concepções de homem e de mundo.

O professor, ao exercer sua prática educativa, ao eleger seu método de ensino ou de avaliação, na forma de se rela cionar com os alunos, em tudo o que diz e até no que não diz, consciente ou inconscientemente, ensina também coisas de que não se dá conta.

Nesse sentido, o estudo das correntes pedagógicas se revela de importância fundamental para situar o papel exercido pelo educador em sua praxis educativa.

Libâneo (1990) classifica as tendências pedagógicas em liberais ou progressistas.

As liberais defendem os valores do sistema capitalista, onde predominam os direitos individuais da sociedade organizada em classes. Dentro dessa concepção, a escola tem por finalidade preparar os alunos para papéis sociais que se utilizem das aptidões individuais. As tendências liberais podem assumir uma forma tradicional, onde a ênfase se coloca sobre conteúdos pré-estabelecidos,transmitidos pela autoridade do professor, que se preocupa com o desempenho intelectual do aluno. Podem se apresentar, também, na forma renovada, que acentua a meta do desenvolvimento das aptidões individuais, mas agora a partir de um processo interno, partindo da descoberta das necessidades, interesses e das experiências do aluno, enfatizando-se também o aspecto interpessoal na relação pedagógica. Já, a tendência liberal tecnicista subordina a educação à sociedade, objetivando instalar comportamentos ou treinar recursos humanos para o desempenho tecnológico necessário à produção.

O outro grupo de tendências - as progressistas, incluem uma análise crítica das realidades sociais, sustentando uma preocupação com as finalidades sociopolíticas da educação. Dentro delas, a tendência libertadora, parte da rea- lidade do educando como "tema gerador", a ser aproveitado como conteúdo da aprendizagem e ponto de problematização e questionamento, visando uma conscientização e transformação da realidade social. A relação professor-aluno é horizontal, sendo que ambos se posicionam como sujeitos do ato de conhecimento, a ser buscado de forma reflexiva e crítica. Na tendência progressista do tipo libertária, busca-se estimular a experiência grupal e de auto-gestão, cabendo ao grupo a iniciativa pedagógica, ficando o professor como um catalisador da aprendizagem, ou um monitor, à disposição do grupo. A tendência progressista, na forma crítico-social dos conteúdos procura instrumentalizar o aluno através de um bom ensino de conteúdos que tenham relevância na vida humana e social. Os conteúdos devem ser assimilados, mas também criticamente reavaliados, face às novas necessidades sociais.

Libâneo ressalta ainda que, na prática, as tendências pedagógicas não estão presentes em sua forma pura, tampouco são mutuamente exclusivas. De qualquer forma, a discriminação dessas tendências mostra-se bastante útil como parâmetro para a avaliação das práticas educativas.

Em função de seus condicionantes culturais, cada tendência implica, portanto, diferentes concepções da aprendizagem, das práticas, dos conteúdos, dos métodos, das avaliações de ensino e da relação professor-aluno.

Modernamente, defende-se que um dos propósitos fundamentais da educação é promover uma aprendizagem significativa. Tal aprendizagem deve incluir o afetivo e o cognitivo, contextualizados no âmbito das necessidades vivenciadas por uma determinada pessoa em seu meio cultural. Lopez (1978) considera que uma pessoa aprenda melhor aquilo que está estreitamente relacionado à sua sobrevivência ou a seu desenvolvimento. Em contrapartida, não se aprende bem o que se considera alheio a si mesmo ou sem importância para a vida. 
Tal concepção de aprendizagem nos possibilita visualizar um elo de ligação entre a psicologia e a educação. Muito da clínica está presente na aprendizagem, e inversamente, há muito de aprendizagem na prática clínica.

Segundo Amatuzzi (1994) é possível empreender uma reflexão acerca das concepções de saúde mental e clínica psicológica partindose dos diferentes sistemas de pensamento representativos das tendências pedagógicas.

Dessa forma, torna-se plausível pensar uma prática clínica (no caso, a psicoterapia breve) em termos de suas articulações com as tendências pedagógicas referidas.

\section{CONEXÕES ENTRE A PEDAGOGIA E A CLÍNICA PSICOLÓGICA}

Pode-se considerar que dentro do pensamento da pedagogia tradicional, saúde e doença estariam definidos a partir de referenciais externos, social e culturalmente estabelecidos. Ao terapeuta caberia realizar o diagnóstico, mediante a aplicação de seus conhecimentos e dispensar ao paciente um tratamento, na forma de instruções ou recomendações.

Já, na pedagogia liberal do tipo renovada, saúde e doença mental seriam categorias mais fluidas, importando a vivência de cada um, sendo que o terapeuta atuaria como um facilitador das descobertas da pessoa.

A pedagogia tecnicista definiria saúde e doença mental em função de critérios de adaptação às necessidades do sistema, sendo os tratamentos voltados a modelar comportamentos.

A tendência libertadora, além da ênfase na vivência e na promoção do processo de cada um, assumiria uma preocupação com a consciência crítica das pessoas acerca dos condicionantes de seu meio sócio-cultural.

$\mathrm{Na}$ tendência libertária, seria evitada a exclusão dos doentes, cabendo à comunidade lidar com seus perturbados. O terapeuta seria um promotor de grupos auto-geridos e igualitários.

Numa concepçãocrítico-social, as teorias e os instrumentos interpretativos da doença mental seriam considerados importantes e criticamente articulados aos condicionantes sócio-culturais do paciente, visando promover uma visão mais profunda da pessoa perturbada.

Essa possível aproximação entre aprendizagem e clínica chega a ser explicitada em algumas abordagens psicoterapêuticas.

Em Psicoterapia Breve (PB) discute-se a importância do insight para a elaboração da conflitiva focal que está sendo trabalhada, questionando-se o tipo, a extensão e a profundidade desse insight.

Alguns autores, como Knobel (1986), defendem que a $P B$ conduza a insights mais cognitivos que afetivos. Outros, dentre os quais Hartmann (1969) é um representante importante, identificam os insights cognitivosàs modalidades de psicoterapias breves que sejam de tipo suportivo ou de apoio, que buscam um fortalecimento egóico. Fiorini (1976), em suas contribuições à $P B$, considera que o insight deva ser uma experiência emocional-cognitiva, equilibrando o papel desses dois aspectos. Ou seja, as mudanças obtidas pelos pacientes em $P B$ são vistas como experiências de aquisição afetiva e cognitiva(ou de aprendizagem), divergindo os autores no tocante ao peso atribuído nessas mudanças ao fator afetivo.

Knobel (1986) enfatiza que a psicoterapia breve não deva estimular a regressão, mantendo a relação em níveis adultos de funcionamento, evitando o surgimento da neurose de transferência e procurando levar a um insight mais cognitivo que afetivo. Acrescenta ainda que a $P B$ deva levar a "uma mutação objetal, através da troca de informação falsa por informação verdadeira". A palavra "informação", empregada pelo autor, é fortemente sugestiva da idéia de promover algum tipo de aprendizado no 
paciente. No caso, um aprendizado sobre si próprio, seu funcionamento psíquico etc, promovendo seu auto-conhecimento.

Referindo-se aos dinamismos de mudanças nas psicoterapias, Fiorini (1976) considera que o trabalho de indagação e verbalização acerca do vivido instaura um processo de crescente objetivação. O autor diz, claramente: "instaura-se, assim, uma aprendizagem, suscetível de ulteriores desenvolvimentos autônomos, centralizada na experiência de conhecer-compreender-objetivar-se, e assentada no suporte da linguagem" (p.143).

Apreende-se, do que foi colocado, uma aproximação da psicoterapia do âmbito das experiências de aprendizagem. Fala-se em insight afetivo e cognitivo, que bem poderia ser traduzido numaaprendizagem significativa, que combina os dois elementos indissociáveis da vivência. Fala-se em informação, em abandonar falsas visões ou falsas crenças, como decorrência de uma oportunidade de repensá-las, chegando à informação "verdadeira". Fala-se de uma experiência de conhecer-compreender-objetivar-se, imbuída nos processos terapêuticos e também atinente aos processos de aprendizagem .

No presente trabalho, pretende-se um exercício de reflexão sobre uma prática pedagógica, à luz das diversas tendências apresentadas. Elegeu-se como experiência de ensinoaprendizagem justamente uma prática clínica, a saber, a psicoterapia breve. Tomou-se um segmento de atendimento clínico nessa modalidade como ponto de partida para a presente análise, que procura avaliar as consonâncias de tal praxis clinica com tal ou qual tendência pedagógica.

Esse exercício, conceitualmente possível, permite ao profissional identificar seu posicionamento em termos de uma contextualização mais ampla, considerando-se os determinantes ideológicos e sócio-culturais que dão sustentação à sua prática.

\section{MÉTODO}

\section{Material}

Versões de sentido (vs) de 9 sessões de psicoterapia breve de uma mulher adulta, 26 anos, solteira, professora do magistério, cursando nível superior em Psicopedagogia e sem antecedentes psiquiátricos.

Os 9 relatos (vs) correspondem a um fragmento do processo psicoterapêutico total, desenvolvido em 12 sessões, realizadas semanalmente, com a duração de 50 minutos.

O fragmento colhido visou compatibilizar o andamento das sessões com a data de término da disciplina do ano letivo que deu origem a este trabalho.

\section{Instrumento}

Versão de Sentido (vs) , proposta por Amatuzzi (1995) para a pesquisa de processos psicoterapêuticos, definida pelo autor como "um relato breve e essencial da experiência imediata do terapeuta, escrito por ele logo após o término do atendimento" (p.65).

\section{Procedimento}

O procedimento se realizou em três etapas:

\section{1) Redação das versões de sentido (vs):}

Ao término de cada sessão, o terapeuta relatava, na forma de um texto livre e espontâneo, sua experiência imediata do encontro recém-terminado ( $v s$ ).

\section{2) Identificação das tendências pedagógi- cas:}

Através de leituras repetidas das vs, extraíram-se possíveis indicadores de tendências pedagógicas supostamente embutidas naquela experiência.

Trata-se de uma tentativa de articular um sistema de pensamento (pedagógico) à uma 
prática (psicoterapia), buscando apreender suas afinidades, coerências ou discrepâncias.

\section{3) Avaliação crítica:}

Segue-se uma avaliação crítica da experiência, considerando-se oito passos didaticamente propostos por Amatuzzi durante a disciplina ministrada.

Tais passos não constituem ítens estanques, nem devem ser mecanicamente aplicados; antes, devem servir como um guia para orientar a reflexão e análise acerca dos dados (vs) obtidos:

1.Contar a experiência: relato espontâneo e o mais autêntico possível da experiência vivida, logo após seu término ( $v s$ ).

2. Resumir os relatos: é útil extrair os pontos-chave, o sentido principal da experiência, sendo que uma frase ou uma palavra pode condensar o significado do encontro.

3. Comparar: a experiência deve ser comparada com outras, com base na literatura disponível.

4. Ampliar: consiste em teorizar, relacionar com outros âmbitos de compreensão, com outros enquadres possíveis (concepções de história, de sociedade, de educação, etc).

5. Discutir: verificar consistências internas em sua prática, pensar conseqüências mais amplas, medir o valor do que se realizou.

6. Propor modificações: dizer o que pode ser feito para melhorar.

7. Explicitar condições: dizer o que essas modificações pressupõem.

8. Aplicar os resultados da avaliação crítica realizada: a reflexão e a análise realizada devem retroalimentar a prática exercida.

\section{RESULTADOS OBTIDOS}

Seguem os relatos na forma de versões de sentido (vs) das sessões de $P B$ realizadas:

\section{Primeira sessão}

Você chegou e foi logo informando que estuda Psicopedagogia, que tem visto muita coisa no curso e tudo isso tem mexido com você.

Lembro-me de que isso me impacientou um pouco, entendi como sendo uma racionalização para não ver seus problemas, e automaticamente, me veio à mente a chatura de atender alguns clientes psicólogos ou psicanalisados, que já vem trazendo o script. Mas, como nunca se sabe, aguardei.

Você seguiu dizendo saber que a vida familiar afeta muito às pessoas, e aí contou como você simplesmente não está conseguindo ficar bem, dentro de sua própria casa. A mera presença de seus pais a incomoda, você se sente pouco à vontade, angustiada ... e respira, aliviada, quando eles se ausentam ou viajam. Você se sente mal na presença deles, não sabe definir bem o porquê disso, fica sufocada...

Você conta que sua vida com eles sofreu muitas transformações. Você abandonou a religião de seus pais e sente que as repercussões disso ainda estão sobre você. Você me passa a impressão de ver sua família como dura e intransigente. Penso que você também parece não estar se perdoando.

Sinto que o tom de sua fala é de muita mágoa. Proponho que a gente procure examinar tudo isso, olhar para os sentimentos que estão pedindo passagem ...

Ao final da sessão, estávamos mais próximas. Até me surpreendeu a velocidade com que a "psicopedagogia" deixou de ter importância.

\section{Segunda sessão}

Informei a paciente sobre a natureza breve do atendimento: enquadre (a duração das sessões, as faltas), o objetivo que teríamos que definir e as combinações acerca da duração do atendimento. Proponho pensar desde já qual 
seria a sua necessidade maior, nesse momento de sua vida, ou, o que veio buscar na terapia...

Ela mergulha na questão do relacionamento familiar- traz as restrições do meio familiar, a sensação de opressão... O rompimento com a igreja, dentro dessa necessidade interna dela de expansão e crescimento. Chora, acreditando que amigos e familiares não a aceitam mais depois disso... Eu a provoco a fazer as mesmas perguntas do lado de dentro; como foi para ela deixar a igreja. Constata o conflito - de um lado, uma libertação, de outro, culpa, rejeição a si mesma. Eu Ihe falo da minha impressão, de ter havido na ocasião, muita comoção no meio familiar, sendo que as coisas não foram nada fáceis para ela, mas que agora, as coisas do lado de fora parecem ter se acomodado. Ela então se lembra de uma festa familiar, para a qual foi convidada, mas se recusou a ir, achando que poderia ficar chato. Ela concorda que pode estar partindo dela essa atitude de se excluir da convivência com os demais.

\section{Hoje foi o dia da culpa.}

Fico pensando quanto sofrimento, quanto temos que lutar para nos darmos o direito de existir e sermos nós mesmos. Eu Ihe comunico isso, minha visão dela como essa lutadora, buscando ser ela mesma, mesmo com muita dor e pagando preços altos em sua convivência social e familiar.

Penso que ela já vem num processo de mudança, acumulando muitas conquistas... A impressão que tenho é a de que tem um pique bom para terapia. Foi legal.

\section{Terceira sessão}

Chegou meio "pra baixo". Quer falar de sua auto-estima (usa esse nome mesmo), que está ruim. Ela diz coisas impressionantes: "nada fica bem em mim" (roupas, brincos ... ). Pergunto como ela se vê, o que pensa dela, fisicamente. Ela comenta que não gosta de seu aspecto, não sabe bem por quê, nem se olha no espelho. Segue-se uma descrição dos valores familiares, de condenação à vaidade, etc. Não conse- gue se definir, se socorre na opinião de outros: "minhas tias me criticavam", "meus pais, não sei, não falavam nada", começa a se confundir, mostra um desconforto visível: "falar sobre isso, me sinto mal, é tão fútil". Falo-lhe de sua proibição de se ver, de olhar para ela (nem olhar no espelho pode). Por que? ... isso é feio, é pecado, é fútil, é egoísta, é o quê? ...

Conversamos de muitas coisas, sua visão infantil de si mesma como gorda, feia, burra... Os pais não a viam, seus aspectos belos não eram apontados, não se lembra de elogios, só de receber críticas... Ela própria, não se via. Tentava bravamente se valorizar dentro da família, sendo organista da igreja, se destacando nas cerimônias da igreja...

Vai saltando aos olhos o estrago que a proibição de se olhar vem Ihe fazendo. Olhar para si, não só fisicamente, encontrar quem ela é, saberde seus anseios, seus desejos, de sua maneira de ser. A culpa e o medo de se dar o direito de olhar para si mesma, cuidar dela, pensar nela, existir.

Essa sessão foi forte. Eu intimamente agradeci a ela por me deixar partilhar dessa forma, de coisas tão sensíveis.

Eu resumiria esse contato: "alguém aprendendo a se ver".

\section{Quarta sessão}

Vem contando que está questionando sua opção pelo magistério. Tem vontade de partir para a coordenação de ensino. Antes, não tinha ambição, só queria dar aulas, agora está pensando que talvez fosse bom ter novas oportunidades. Acha que essa perspectiva existe, na escola onde leciona.

Aponto essa abertura que ela está tendo ao novo, às oportunidades de crescimento. Pergunto quando isso começou.

Ela conta de uma viagem feita ao Maranhão, projeto Rondon, vontade de levar algumas idéias (ou ideais) adiante, também pela experiência de estar pela primeira vez fora de casa, de arrumar um namorado ... Fala de uma série de experiências novas. 
Eu the comunico que essa necessidade de crescimento pessoal parece presente desde sua chegada, que ela se mostra ativamente voltada para seu processo de individuação. A terapia viria para confirmar ou firmar essa tendência dentro dela, como alguém que está na estrada, mas procura uma sinalização para se assegurar de que essa é a direção a seguir. Ela concorda com a minha impressão. Ficamos de pensar no fator tempo da terapia numa próxima sessão. Acho que já temos um foco, uma direção a seguir.

\section{Quinta sessão}

Justo agora que pensa em se livrar das aulas e dar outro rumo à sua vida profissional, não conseguiu dizer não à diretora, que the solicitou cobrir uma saída de um professor. Ela aceitou outras turmas e mais aulas e está com raiva de si mesma. Capitulou, premida pela autoridade da diretora.

Isso rendeu... falamos de como era isso em casa, diante da autoridade dos pais. Em casa, não podia tolerar que os pais a pusessem "no gelo". Ela ficou pequena, diante da diretora, com medo da perda do amor, da rejeição.

É difícil pensar no que eu mtervi, no que veio dela, a sensação é de um texto escrito em quatro (ou duas) mãos. Uma pergunta minha, uma fala dela, um comentário que eu começo e ela completa, alguma coisa que ela diz e eu simplesmente re-digo. Em outras palavras, a sensação é de uma composição que fizemos juntas, como um tecido, que vai tomando corpo, e ninguém sabe mais quem passou qual fio...

\section{Sexta sessão}

Não veio. Estranhei sua ausência.

Contou depois que perdeu hora, dormiu demais, estava cansada, se desorganizou com a sobrecarga das aulas.

\section{Sétima sessão}

Chegou com ar cansado, dizendo-se estressada com sobrecarga de trabalho. Ressentida também com a solidão em casa, os pais viajaram, justo agora que ela não tinha tempo pra mais nada e ainda tinha que prover sua infra-estrutura. Comenta de sua dificuldade de se alimentar - não gosta de sua própria comida. Já, com a comida que sua mãe faz, isso não acontece - acomidada mãe é diferente, tem um cheiro que enche a casa, dá vontade de saborear. Aponto uma diferença - antes, se incomodava com a presença, agora se queixa da ausência dos pais. Ainda precisa falar com raiva - os desgraçados que desaparecem justo quando ela precisa deles - mas, sinto na sua comunicação, o sentimento inverso, a falta que eles estão fazendo, a saudade da comida cheirosa da mãe, das coisas boas dessa convivência.

Falei demais, me empolguei. Acho que dei a interpretação do sentimento de amor muito de bandeja. Mas acho que não prejudiquei. Ela pôde enxergar, admitiu. Rimos muito nessa sessão e o clima mudou. Passou do cansaço para o reconhecimento de que precisa dos pais para se refazer emocionalmente, eles são seu alimento e dão mais força para enfrentar o dia a dia. Não só de pão vive o homem, eu a lembrei, mas também das trocas afetivas.

Foi gostoso. É realmente um privilégio participar da vida de alguém dessa forma tão íntima.

\section{Oitava sessão}

Por iniciativa minha, fizemos um midpoint hoje (midpoint reviewou revisão de meio de processo, na concepção de Rudolph (1993) consiste numa avaliação conjunta do andamento da terapia, realizada pelo paciente e terapeuta, aproximadamente no meio dos processos breves). Procuramosavaliar o quanto andamos e a quantas andam as suas necessidades com relação à terapia. Você me diz que sente que tem meio caminho andado. Discordo de você, dou-Ihe minha visão de cinqüenta por cento como mais ou menos, um sim e um não, andou e não andou na terapia. Parece-me que você já superou a pior parte com relação a seu 
problema inicial, não está mais da mesma forma que chegou, andou um bocado, mais que a metade. Então você concorda com a minha visão. É que você pensa que ainda tem muito o que caminhar. Entendemos que o auto-crescimento, é de fato, uma coisa sem fim. Voltamos à questão de nossa proposta na terapia, algo mais restrito, de entender e superar o entrave inicial que a impedia de se ver, que lhe dificultava se dar liberdade nesse crescimento. Combinamos o término para daqui a um mês.

Você retoma seus assuntos, existe um tom queixoso na sua fala, você se faz muitas perguntas, sem pensar sobre nenhuma delas. Isso me impacienta um pouco, mas procuro não demonstrar, respiro fundo e aguardo seu movimento, no emaranhado de questões que você se faz. Você está tentando se avaliar como professora, junto a seus alunos, tenta se ver nesse papel. Sua hiperpreocupação em estar preparada para as aulas, sua exigência de dar uma aula perfeita. A conversa vai revelando uma necessidade sua de se sobressair, de demonstrar conhecimento e sobrepujar qualquer aluno. Uma disputa pelo poder, travada com relação ao conhecimento, você tem que estar sempre à frente dos alunos. Sinto que tem a ver com a nossa relação e lhe pergunto isso. Ela não identifica ainda. Eu a confronto, lembroIhe de que sua primeira comunicação ao procurar terapia era a de que estudava psicopedagogia, de que não era uma leiga qualquer, conhecia o assunto. Causo um certa surpresa e embaraço, mas ela, aos poucos, consegue assumir esse aspecto e ainda avançar, fazendo algumas revelações sobre preocupações dela no atendimento. Foi uma conversa um pouco difícil para ela, lutando com algumas inibições, mas, ao final, o saldo foi bom. Rimos um pouco de como às vezes nos deparamos, de repente, com algo inesperado.

\section{Nona sessão}

Hoje foi bom.

Fico confiante em apontar alguns aspectos que podem incomodá-la - por exemplo, seu lado autoritário. Faço-o sem temor, e aí acolho o que vem, seu desconcerto, alguma vergonha, questionamentos... Sinto que há uma confiança recíproca, ela pode se revelar e eu posso dizer com tranqüilidade o que vejo.

Avançamos, rimos. A sessão é equilibrada, sinto que ela tem recursos com os quais posso contar. Vejo crescimento.

\section{DISCUSSÃO}

Inicia-se essa análise crítica pelas possíveis articulações entre os relatos das sessões psicoterápicas (vs) e as tendências pedagógicas que poderiam estar subjacentes.

A primeira sessão aproximou-se mais de uma experiência condizente com a pedagogia renovada. A ênfase foi colocada na promoção do processo autônomo da paciente, a terapeuta se oferecendo para ser facilitadora dessas descobertas pessoais.

$\mathrm{Na}$ segunda sessão, a experiência de aprendizagem sugeriu um misto da tendência renovada e da libertadora. Discutiu-se a coragem de romper com restrições e expectativas de seu grupo social e familiar (representada por deixar a igreja) em prol da busca de uma vida mais autêntica, orientada a partir das necessidades de crescimento da paciente.

A terceira sessão se assemelhou à anterior - procurou-se incitar a paciente a um questionamento acerca de valores de seu meio cultural, incentivando-a a olhar para si e a se descobrir como sujeito. Em alguns momentos, para a terapeuta, foi difícil aguardar os movimentos espontâneos da paciente. Mesmo partindo da vivência que a paciente trazia, as respostas lhe foram oferecidas ("isso é feio, é fútil. .."), dando pouca chance a uma verdadeira descoberta.

A quarta sessão serviu para o estabelecimento do foco. O foco emergiu, fez-se claro, como acontecem nas descobertas nas quais a fundamentação da escola renovada está presente. 
A quinta sessão foi uma construção conjunta de conhecimento sobre a paciente, possível a partir da vivência da paciente e de uma aproximação afetiva muito grande entre paciente e terapeuta, como possibilita a tendência renovada.

Com respeito à sexta sessão, respeitou-se o direito a não vir da paciente. Suas explicações, dadas posteriormente, foram aceitas sem questionamentos. Aqui a tendência libertadora pareceu fazer eco na terapeuta, seu papel não Ihe conferindo qualquer autoridade, respeitando-se a liberdade da paciente.

Na sétima sessão, deu-se a descoberta e exploração de conteúdos emocionais, nos moldes de uma experiência renovada. A terapeuta, de novo, talvez tenha se antecipado em alguns momentos ("falei demais ..."), mas ainda assim, a tônica de respeito à experiência de vida da paciente prevaleceu, partindo-se dessa experiência.

Na oitava sessão, foi o momento de estabelecimento do prazo ou término da terapia. $\mathrm{A}$ atitude aqui foi mais diretiva, quase tecnicista. Colocou-se o assunto em discussão, mas a decisão fluiu da terapeuta, que exerceu seu papel técnico como alguém que administra um programa. A reação da paciente foi meio regressiva (piora, se confunde), depois competitiva, procurando recuperar o lugar de decisão e poder que busca ter na vida (à frente dos alunos) e na terapia. Tudo isso foi usado em prol de seu auto-conhecimento, conforme a tendência renovada.

Na nona sessão, última desse fragmento de um processo, prosseguiu um clima de confiança onde as comunicações foram fáceis, democráticas, catalisando novas descobertas. De novo, se fez sentir a tendência renovada.

Observando-se globalmente os dados deste trabalho, verifica-se um predomínio da tendência renovada, e em alguns momentos, a presença da tendência libertador a, durante as interações ocorridas no processo depsicoterapia breve realizado.
Acredita-se que esse resultado provavelmente se explique pela própria natureza da intervenção psicológica, no sentido de priorizar a emergência das vivências próprias da pessoa, facilitar as descobertas e as condições para um processo autônomo, aproximando-se, desta forma, muito mais da tendência renovada que de qualquer outra.

Em suma, posturas, atitudes, falas do terapeuta, são importantes para favorecer um campo onde determinadas vivências se tornam ou não possíveis. A psicoterapia, ao pretender a expressão do paciente, a mais livre e verdadeira possível, valoriza a fala autêntica, que só pode emergir quando algumas condições estão presentes.

Repensar a própria atuação como psicoterapeutas, à luz das tendências pedagógicas, pode abrir caminho para o entendimento dessas questões, fundamentais à prática clínica.

\section{COMENTÁRIOS E SUGESTÕES}

Tratou-se de uma experiência de atendimento psicoterápico em $\mathrm{PB}$, relatada na forma de versões de sentido, e posteriormente pensada enquanto formas do processo de ensino-aprendizagem, em sentido amplo.

Os resultados obtidos aprovaram o método da versão de sentido como adequado para propiciar não só a análise de processos psicoterapêuticos (finalidade esta para a qual foi criado), mas também como ponto de partida para análises críticas de experiências de aprendizagem.

O ganho dessa reflexão, a partir do fragmento de material clínico disponível, foi o de possibilitar a identificação de quais tendências pedagógicas estariam presentes nessa prática clínica. Como profissionais de saúde mental, torna-se imprescindível saber situar essa práticajunto aos pacientes dentro de um referencial não só psicológico, mas também social, cultural e ideológico. 
Quando não se tem claro tal inserção cultural, pode-se partir de uma visão equivocada, conduzindo a conclusões, no mínimo, parciais.

Pesquisadores do campo das ciências sociais têm demonstrado, a partir do estudo das representações sociais, como socialmente se constróem significados que orientam as práticas e comportamentos da vida diária. Neri (1988), estudando a velhice, constata que muitos profissionais de saúde contribuem para a perpetuação de mitos, preconceitos e estereótipos com relação ao grupo de idosos. Temos aqui uma ilustração de como, desavisadamente, pessoas informadas podem propagar atitudes anti-científicas, caso não se dm conta de estarem reproduzindo acriticamente conteúdos que permeiam o imaginário social.

É papel primordial da psicoterapia levar ao auto-conhecimento. Tende-se a pensar esse conhecimento como unicamente psicológico, esquecendo que não há psíquico que não seja também biológico, social, cultural, ideológico... Não há psíquico sem que haja o homem, resultado e síntese de todas essas dimensões que Ihe são constitutivas.

Na prática das psicoterapias, mesmo sem o saber ou desejar, transmitem-se aos clientes valores, crenças, posturas, visões de humanidade e de mundo. Um exercício de reflexão, como o empreendido neste trabalho, nos coloca face a essa realidade de maneira palpável.

É importante observar que, nas psicoterapias, há sempre um recorte maior com relação ao campo do psíquico, dado que as psicoterapias se propõem à investigação dessa dimensão do ser humano. É necessário, no entanto, que se tenha consciência dessa ênfase depositada no campo do psíquico, para que se pratique um recorte, e não um reducionismo. Tal reducionismo implicaria uma visão equivocada do homem, a permear a prática clínica de atitudes desrespeitosas e parciais, própria de uma concepção de homem desarticulado de suas outras dimensões constitutivas - de natureza física, antropológica, social, cultural, espiritual... (se é que, com essas dimensões, esgotamos o humano!). Possivelmente, em alguns momentos da terapia, esses aspectos possam ser encampados nas conversas com o paciente, com isso, enriquecendo sua consciência de si, articulando-a com a conscientização dos aspectos indissociáveis da realidade circundante mais ampla. Ainda assim, deve-se partir das vivências do paciente, reconhecendo-se as reverberações internas desses aspectos em seu psiquismo, para não correr o risco de fazer da psicoterapia proselitismo, aula de sociologia, catequese...

\section{CONSIDERAÇÕES FINAIS}

Acredita-se que o psicoterapeuta, além das recomendações técnicas de praxe, deva buscar, em sua prática clínica, uma ampliação de seu espectro pessoal, visando melhor responder à multiplicidade e complexidade das demandas com as quais se depara.

Além de investir em sua formação e em sua análise pessoal, deve buscar promover seu conhecimento e sua inserção em outros campos do humano. Investir na própria cultura, aproximar-se da filosofia, da religião, da história, da música, da política, buscar conhecer as diversas manifestações culturais, aproximarse da expressão artística... enfim, ser participativo da realidade humana em um sentido mais amplo.

O psicoterapeuta, de alguma forma, ensina coisas a seu cliente. Lições de relacionamento (sobretudo pela relação com ele, terapeuta), de enfrentamento de questões de vida, de encorajamento do olhar para si, de valorização da experiência pessoal, e outras tantas... Mas, sobretudo, o psicoterapeuta pode aprender, aprender com seu cliente, com os sucessos e insucessos da relação, e sobretudo, com uma reflexão crítica acerca dessa experiência.

Com o presente trabalho, procurou-se ilustrar uma maneira de fazer a avaliação de uma 
experiência relacionada a ensino-aprendizagem, tomada num sentido mais amplo e flexível. Contribuições da pedagogia tornaram-se ponto de partida para um olhar sobre a clínica psicológica. Espera-se ter contribuído, de alguma forma, para gerar alguma inquietação, sem a qual não há crescimento, nem mudança...

\section{REFERÊNCIAS}

AMATUZZI, M.M. (1994) Métodos de ensino. Campinas, PUCCAMP [Digitado].

AMATUZZI, M.M. (1995) Descrevendo processos pessoais. Estudos de Psicologia, 12 (1):65-79.

FIORINI, H. (1976) Teoriae técnica de psicoterapias. Trad. Carlos Sussekind. 8 ed. Rio de Janeiro: Francisco Alves, 1989.

HARTMANN, H. (1969) Ensayos sobre la psicologia dei yo. México: Fondo de Cultura Económica.
KNOBEL, M. (1986) Psicoterapia breve. São Paulo: EPU.

LIBÂNEO, J.C. (1990) Tendências pedagógicasna prática escolar. In:Democratização e escola pública: a pedagogia crítico-social dos conteúdos. 9 ed. São Paulo: Loyola.

LOPEZ, S.M. (1978) Métodos y objetivos en el contexto dei proceso enseíñanza aprendizaje. DICAC, Boletim del Centro de Didáctica de la Universidad Iberoamericana. México.

NERI, A.L. (1988) Envelhecer num país de jovens: significados de velho e velhice segundo brasileiros não-idosos. Tese de Livre Docência. Campinas, Faculdade de Educação da UNICAMP.

RUDOLPH, B.A. (1993) The importance ofthe midpoint review in time-limited therapies. Professional Psychology Research and Practice, 24 (3), 346-352. 